\title{
Os contos de Ântia: narrativas intercaladas em Efesíacas, de Xenofonte de Éfeso
}

Duarte, Adriane da Silva

Os contos de Ântia: narrativas intercaladas em Efesíacas, de Xenofonte de Éfeso ${ }^{1}$

Synthesis, vol. 26, núm. 2, 2019

Universidad Nacional de La Plata, Argentina

Disponible en: http://www.redalyc.org/articulo.oa?id=84662943004

DOI: https://doi.org/10.24215/1851779Xe061

Esta obra está bajo una Licencia Creative Commons Atribución-NoComercial-Compartirlgual 4.0 Internacional. 
Artículos

\title{
Os contos de Ântia: narrativas intercaladas em Efesíacas, de Xenofonte de Éfeso ${ }^{1}$
}

\author{
Anthia's tales, Embedded Narratives in Xenophon of Ephesus' Ephesika
}

Adriane da Silva Duarte

Universidade de São Paulo, Brasil

asduarte@usp.br

(iD) http://orcid.org/0000-0002-7133-3115

\author{
DOI: https://doi.org/10.24215/1851779Xe061 \\ Redalyc: http://www.redalyc.org/articulo.oa?id=84662943004
}

\begin{abstract}
Resumo:
Dentre os autores do romance grego antigo, Xenofonte de Éfeso é considerado o menos habilidoso em vista do estilo. No entanto, destaca-se enquanto narrador pelo emprego que faz das narrativas intercaladas, histórias embutidas no quadro mais amplo do romance. Esse artigo propóe-se a examinar o emprego desse recurso relacionando-o com Ântia, que é a uma só vez narradora e objeto de narrativa intercalada em Efesíacas. Argumenta-se que a estratégia promove a intertextualidade com a Odisseia e contribui para caracterização da personagem como dotada de habilidade retórica e astúcia.
\end{abstract}

Palavras-chave: Xenofonte de Éfeso, Efesíacas, Romance Grego Antigo, Narrativas intercaladas.

\begin{abstract}
:
Although Xenophon of Ephesus is considered as an author with relatively few literary merits, he stands out for his skill in composing embedded narratives, stories within the main story playing an important role in the action's development. The purpose of this paper is to examine how the author takes advantage of this secondary narratives particularly regarding a singular character, namely, Anthia, the Ephesiaka's heroine, Anthia, who is at once narrator and subject of narratives contained within the novel's major framing narrative. I sustain that such strategy is carried out in a close intertextual connection to the Odyssey and contributes to her characterization as a woman specially endowed for rhetoric and cunning.
\end{abstract}

KEYWORDs: Xenophon of Ephesus, Ephesiaka, The Ephesian tales, Greek Ancient Novel, Embedded narratives.

As Efesiacas, de Xenofonte de Éfeso, é o menos extenso dos romances gregos de amor (ideal love novels). ${ }^{2}$ Apesar disso, não há dúvidas de que seja o mais difícil de resumir em vista de sua trama acidentada, que inclui seguidas peripécias e duplicação de padrões narrativos. Para alguns, isso se deve ao fato de a obra constituir ela mesma um resumo, ou epitome, do original -a Suda registra que Efesíacas seria composta por dez livros, mas o texto que sobreviveu tem apenas cinco, como atesta o parágrafo final (Efesíacas V.15.4): "É o final das Efesiacas de Xenofonte, relato em cinco livros, a respeito de Ântia e Habrocomes”. ${ }^{3}$ Essa incongruência, como nota Ruiz-Monteiro (2004, p. 43), está diretamente relacionada à problemática recepção crítica que o autor tem recebido:

Dos cinco autores dos assim denominados romances “de amor e aventura” talvez o menos estudado seja Xenofonte de Éfeso. Isso se dá porque, desde que a Suda atribuiu dez livros a Efesíacas enquanto o texto do romance contém somente cinco, Xenofonte foi tradicionalmente visto como tendo menor mérito literário. E apesar da defesa de T. Hägg, que sustentou que a reputação de Xenofonte como compositor de epitome baseia-se sobretudo em sua técnica narrativa particular e em que, em todo caso, o texto devesse incluir algumas lacunas, a teoria da epitome perdurou por anos.

A isso se soma à percepção de que, por seu estilo descuidado e desprovido de ornamentação, sobretudo quando comparado aos dos demais romancistas, Xenofonte era um escritor de poucos recursos, o que foi motivo para que sua obra tenha sido largamente negligenciada (Ruiz-Montero, 2004, p. 43). Kytzler (2003, p. 350) sintetiza bem a questão ao anotar que: "É óbvio para qualquer leitor da obra de Xenofonte, seja no 
original, seja em qualquer uma de suas numerosas traduções, que ele se vale de uma linguagem pouco refinada, mais para o simples".

Quanto à teoria da epitome, embora bem aceita no passado, passou por revisão a partir da análise pioneira de Hägg (1966), seguida dos estudos de O'Sullivan (1995) e Ruiz-Montero (2004), entre outros, que defendem que Efesíacas é um texto transicional, que, embora escrito, guarda fortes marcas de oralidade. Assim, certas características estilísticas, como repetição de estruturas (repetitive-formulaic character), sejam sintáticas, semânticas ou temáticas, antes apontadas como defeitos de composição e postas na conta da epitome, passaram a ser vistas como recursos empregados conscientemente por um autor devedor da tradição narrativa oral. Nas palavras de O'Sullivan (2014, p. 50), Efesiacas:

[...] deveriam ser consideradas como um texto transicional, uma obra ainda fortemente ligada à sua origem oral, mas que foi composta por escrito e que é até mesmo capaz de incorporar - embora eu não veja isso de maneira tão clara em Xenofonte - características literárias e, inclusive, intertextuais. ${ }^{4}$

No que respeita esse último tópico, Tagliabue (2017), em estudo recente, apontou referências a Odisseia e aos diálogos platônicos em Efesíacas, embora elas se deem de maneira muito mais sutil do que se encontra no contemporâneo Queréas e Calírroe, de Cáriton de Afrodísias, por exemplo. ${ }^{5}$

Quer se aceite a hipótese da influência de um estrato de base oral ou não, o fato é que, em vista da complexidade de sua estrutura narrativa, que conjuga vários planos de ação e personagens, sujeitos a sucessivas peripécias, Xenofonte parece ter aberto mão da refinamento da composição, em seus vários níveis, linguísticos e estruturais, em troca da agilização do ritmo narrativo. Apesar do desprestigio de Xenofonte com a crítica, uma análise mais isenta do romance é capaz de revelar sua competência enquanto narrador.

Efesíacas apresenta um narrador onisciente e em terceira pessoa, bastante discreto, que quase não se mostra na narrativa, em marcado contraste com Cáriton de Afrodísias, que traz um narrador intrometido. Segundo Morgan (2004, p. 490): "a função mais visível desse quase invisível narrador é precisamente controlar as rápidas transições entre as duas linhas narrativas da trama", basicamente entre as aventuras de Ântia e as de Habrocomes, separados desde o início da narrativa, em que cada qual cumpre uma trajetória diferente. Essas mudanças podem parecer por vezes abruptas, deixando certos episódios sem um pleno desenvolvimento. No entanto, em ao menos um aspecto, Xenofonte parece ter se destacado: no que concerne às narrativas intercaladas (embedded narrative), ou histórias que estão embutidas dentro da narrativa principal (tale within the tale), e que têm por emissor quer um dos personagens, quer o próprio narrador (mais raro no caso desse autor). Além de cumprirem a função de informar as personagens dos passos umas das outras (é o que acontece no relato de Hipótoo e de Crisio), se oferecem enquanto analogias exemplares para os heróis, contribuindo também para sua caracterização. ${ }^{6}$

As principais narrativas intercaladas em Efesíacas são atribuídas a personagens coadjuvantes, como Hipótoo (Efesiacas III.2.1-15) e Egialeu (Efesiacas V.1.4-11), que relatam a Habrocomes experiências pessoais e marcantes e que, de alguma maneira, se relacionam à vivência amorosa do narratário. Nos dois casos, o narrador informa que Habrocomes conta-lhes em retorno a sua história, mas como esta é conhecida do leitor, não há necessidade de reproduzi-la.

Isso vale também para Ântia, a heroína do romance. Eis um exemplo, entre outros. Forçada a desposar um reles pastor, cuja condição social era em muito inferior à dela, Ântia lhe revela sua origem aristocrática e livre, suplicando para que ele não consumasse o casamento. Diz o narrador (Efesíacas II. 9):

[Ântia] Contou quem era, de sua origem ilustre, de seu marido, da captura. Depois de ouvi-la, Lampão apiedou-se da moça, jurou mantê-la intocada, e recomendou que tivesse coragem.

O mesmo acontece quando, assediada por Hipótoo, Ântia “[...] primeiro, recusou-o, dizendo ser indigna do leito de um rico senhor, mas, por fim, como Hipótoo insistisse, sem ter outra opção, julgando ser melhor revelar-lhe seus segredos do que violar o que havia combinado com Habrocomes, falou de Habrocomes, 
de Éfeso, da paixão entre eles, dos juramentos, das desventuras, dos piratas e lamentou constantemente o marido" (Efesíacas V.9).

Basta, assim, a enunciação de poucos tópicos para que o leitor reconstitua o teor do que teria sido relatado. Em vista a essa economia narrativa, geralmente, os personagens principais, não protagonizam narrativas intercaladas na obra de Xenofonte.

\section{A Histórias que ÂNTIA conta}

Há, contudo, uma situação diferente, em que Ântia faz um breve relato ao rufião, que a tinha comprado na Itália, para explicar a origem da suposta doença que a impedia de trabalhar no prostíbulo. Eis a história (Efesiacas V.7.6-9):

Quis contar para você antes a minha condição e explicar o que aconteceu, mas, por pudor, ocultei. Mas agora, contar não é nem um pouco difícil, já que tudo se sabe a meu respeito. Ainda criança, estava em um festival e, durante a vigília noturna, me perdi dos meus acompanhantes. Fui parar no túmulo de um homem recém-falecido. E ali, alguém pareceu saltar do túmulo e tentou me segurar, e eu me debatia e gritava. A criatura tinha um aspecto medonho, mas sua voz era muito pior. E quando, enfim, veio o dia, ao me deixar ir, golpeou-me no peito e dizia ter lançado ali essa doença. E desde então, diversas vezes e de várias maneiras, sou acometida por essa desventura.

Momentos antes, ela fingira convulsões e desmaio, à maneira dos "que sofriam com a chamada doença divina" - designação dada à epilepsia, segundo os comentadores. Assim como o ataque fora fingido, o relato revela-se igualmente mentiroso. Ao contrário do que fizera com Lampão, em cujo caráter confiava, acreditando que ele fosse respeitá-la ao conhecer sua verdadeira história, Ântia não crê que o rufião teria os mesmos escrúpulos morais e inventa a doença e sua causa para escapar à sorte que lhe estava reservada. Baseada nas crenças bastante difundidas de que certas doenças tinham origem na possessão por deuses e daimones, 7 ela imagina esse conto de terror em que a criança se perde da família durante à noite e involuntariamente vai parar no cemitério. Ali vê surgir de um do túmulo uma aparição, um homem recém-enterrado que tenta agarrá-la, mas ao se ver frustrado, lança em seu peito a tal doença como punição.

Histórias de assombração eram apreciadas no período em que Xenofonte compôs Efesíacas, como demonstra sua presença no Satíricon (cf. LXII, relato sobre o encontro com um lobisomem no cemitério; LXIII, relato do roubo de um cadáver durante o velório por bruxas), em $O$ asno de ouro (I. 5-20, relato sobre aparição de bruxas vingativas; II. 21-30, Telifrão conta como foi mutilado pelas bruxas durante a vigília de um morto; ambos, de certa forma, enquadrando a narrativa principal da transformação do protagonista em asno por artes da feitiçaria) e, notavelmente no diálogo de Luciano $O$ amante da mentira ou o Incrédulo. Philopseudes sive incredulus), que se propõe como uma denúncia a essas falsidades, que muitos propagavam por prazer, mas que o narrador/autor, note-se, não se furta a reproduzir. Esses relatos faziam parte da conversa esperada em sociedade, sendo usados para entreter companheiros de viagem ou convidados -a maior parte deles ocorre no contexto de reuniões sociais, como banquetes e festas. Sua presença nos romances de Petrônio e Apuleio sugere que tenham se tornado um topos narrativo no gênero, relacionado aos contos milésios, narrativas em prosa, de temática erótica ou sobrenatural, atribuídos a Aristides de Mileto (II a.C.).

O relato de Ântia deve ser visto dessa perspectiva. Ao narrar um conto de assombração, satisfaz-se o leitor amante de tais histórias. Ao mesmo tempo, o relato dá testemunho da habilidade retórica da heroína. Ântia usa o discurso de modo a manipular seu interlocutor, predispondo-o a agir de acordo com o seu interesse. Note-se ainda que ela dá mostras de ser dotada de astúcia ao criar ficções que sirvam aos seus propósitos, remetendo a Odisseu, o narrador mentiroso arquetípico, na Odisseia, ou, comparação ainda mais pertinente, a Penélope, que pretexta a confecção da mortalha para Laertes, trabalho que ela não pretende concluir, para adiar as núpcias forçadas com os pretendentes - nem preciso lembrar aqui a correlação entre as noções de tecer / tramar e narrar, bastante difundida entre os gregos. Em comum com Odisseu há o relato mentiroso; 
com Penélope, a ação enganosa -Ântia finge o ataque epilético para evitar a prostituição, assim como a esposa de Odisseu tece o manto para Laertes para evitar as bodas.

Ântia se vale desse expediente em outros passos do romance. Veja-se especialmente a mentira que a heroína conta ao negociante indiano Psammis, que a compra em Alexandria (Efesíaca III.11):

Assim que a comprou, o bárbaro, encantado com sua beleza, tentou imediatamente forçá-la e manter relações com ela. Como não queria, primeiro ela se recusou; por fim (e os bárbaros são por natureza supersticiosos), alegou que seu pai, quando do seu nascimento, a consagrara a Ísis até a idade de casar-se. Disse que faltava ainda um ano e que:

- Se você insultar a protegida da deusa, ela se enraivecerá e o castigo será severo.

Psammis convenceu-se, reverenciou a deusa e afastou-se de Ântia.

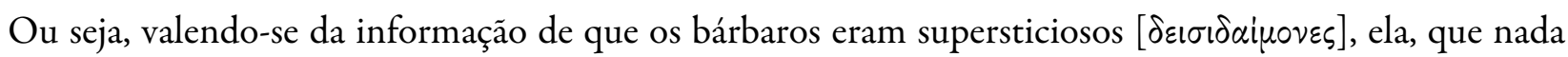
revela de sua verdadeira história, usa um argumento capaz de persuadir Psammis a adiar seus planos de unirse a ela. Em outro episódio, quando um certo Perilau, que a salvara dos bandidos, se apaixona por ela e quer

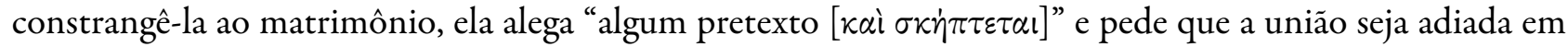
um mês (Efesíacas II.13). ${ }^{8}$

Em recente estudo sobre as Efesíacas, ao analisar a cena de reunião entre Ântia e Habrocomes (Efesíacas V.14), Tagliabue (2017, p. 40) defende que a heroína "é retratada como uma combinação dos dois protagonistas da Odisseia: ela é ambos, Odisseu, porque viaja e detém a posse da palavra por mais tempo, e Penélope, porque inventa estratagemas para manter-se fiel ao marido". Desse modo, ele conclui, o romance propõe um novo tipo de heroísmo calcado na fidelidade, que se impõe graças às virtudes da protagonista naturalmente ele contrapõe Ântia a Calírroe, personagem central do romance de Cáriton de Afrodísias, que contrai segundas núpcias, estando vivo seu marido, ainda que constrangida a tal pelas circunstâncias.

Tagliabue explora a relação intertextual entre o poema homérico e o romance de Xenofonte, chamando atenção para como Ântia, no momento de reencontro do casal após a longa separação a que foram submetidos, descreve para Habrocomes sua atitude durante esse período (Efesíacas V.14):

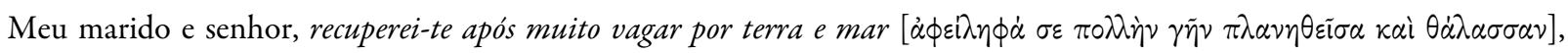
escapando de ameaças de bandidos, de tramoias de piratas, de insultos de rufiões, de correntes, covas, troncos, drogas e

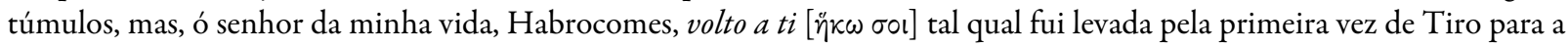
Síria. Ninguém me persuadiu a errar, nem Méris, na Síria; nem Perilau, na Cilícia; nem, no Egito, Psammis ou Poliído; nem Anquíalo, na Etiópia; nem, em Tarento, meu proprietário, mas permaneço pura para ti tendo usado de todo ardil em prol da

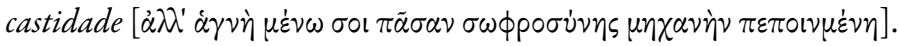

Para ele (Tagliabue, 2017, pp. 39-40), as frases em destaque na citação acima reforçam a identificação com o poema de Homero na medida em que Ântia destaca a errâncias (e vale notar que, embora Habrocomes também tenha percorrido vasta distância por terra e mar, é ela que alcança por último Rodes, onde finalmente se dá o reencontro) e os ardis de que se valeu para afastar os pretendentes. Note-se ainda que ela declara

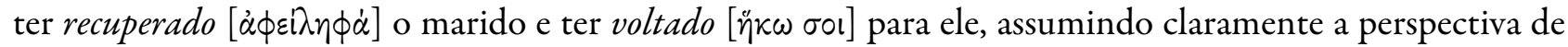
Odisseu, sem deixar, contudo, de acenar para Penélope ao recordar os ardis [ $\mu \eta \chi \alpha \nu \eta े \nu]$ que lhe garantiram a

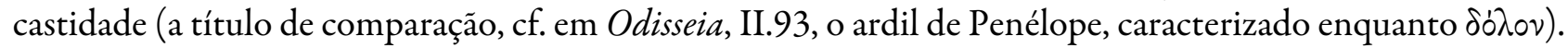

A análise de Tagliabue progride para o modo empregado pela heroína para conservar-se fiel ao marido, deixando inexplorado o teor desses estratagemas, que, como visto, estão na maior parte das vezes associados à prática do discurso enganoso -embora Ântia também tenha apelado à violência, como quando apunhala e mata o bandoleiro Anquíalo que a atacara no covil dos ladróes (Efesíaca IV.5), episódio que se poderia aproximar da aventura de Odisseu na caverna de Polifemo (Odisseia IX.177ss.), tendo por elementos comuns a figura de um transgressor violento, da caverna, da arma perfurocortante.

Voltando à narrativa intercalada de Ântia para o rufião, o segundo propósito é, como notamos de início, inserir na narrativa o topos da história de assombração, ainda que num contexto bem diferente do que costuma constar nos outros romances, já que aqui não ocorre no âmbito de uma reunião social. No entanto, à maneira 
do que se encontra em $O$ asno de ouro, o relato traz elementos coincidentes com a situação vivida pela heroína: o homem que salta do túmulo quer se apossar da menina que resiste ceder a ele, mesmo que a intenção dele não seja de cunho sexual. Essa aparição, tão ameaçadora, de certa forma remeteria a todos os pretendentes de Ântia, que, ao longo de suas errâncias, ameaçaram-na física e moralmente, especialmente o rufião, que a exploraria no bordel. Trata-se de uma história mentirosa, mas que traduz, de certa maneira, os temores, experiências e atitudes da heroína, ou seja, a resistência.

Após ouvi-la, o rufião, embora contrariado, pois já antevira o prejuízo que teria, acreditou nela e abandonou seus projetos, ficando, assim, demonstrada a eficiência do estratagema, a uma só vez inspirado em Odisseu e em Penélope, de que Ântia lança mão.

\section{Histórias SOBRE ÂNTIA}

Ântia não só assume o papel de narradora em Efesiacas, mas também é objeto de narrativas, ao menos em um episódio do romance. Quando Hipótoo e seu bando estão nas cercanias de Tarso, na Cilícia, realizando assaltos e buscando informações sobre o paradeiro de Ântia, refugiam-se, ao cair da noite, em seu covil. Crisio,

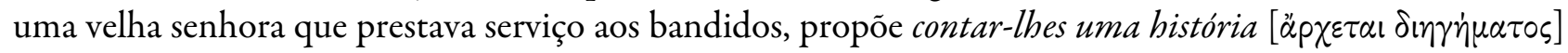
sobre um acontecimento patético ocorrido recentemente na cidade (Efesiacas III.9):

Forasteiros, escutem uma história triste $[\pi \dot{\dot{\alpha}} \theta 0 v \varsigma]$ que se passou recentemente na cidade. Um certo Perilau, homem dos mais importantes, designado para promover a paz na Cilícia, tendo saído em uma busca contra os bandidos, trouxe alguns que capturara e com eles uma linda moça, que convenceu a aceitá-lo por marido. E já estava tudo pronto para o casamento, mas ela, ao entrar no quarto nupcial -talvez por estar tomada de loucura, talvez por amar um outro-, bebe uma droga qualquer e morre. Dizem que sua morte foi desse jeito.

Não demora para Hipótoo constatar que a moça em questão não era outra, se não a Ântia que procuravam. Habrocomes, até então entregue a uma certa apatia, ouve o relato e suplica para que a velha senhora lhe mostrasse o túmulo de sua amada. Diante de sua insistência, Crisio retoma seu relato (Efesíacas III.9):

O maior dos infortúnios [ $\tau \grave{\partial} \delta v \sigma \tau \nu \chi \dot{\varepsilon} \sigma \tau \alpha \tau o \nu]$ coube à pobre da moça. Perilau sepultou-a suntuosamente e cheia de adornos, e, informados sobre o enterro, piratas arrombaram a sepultura, levaram as joias e sumiram com o corpo. No momento Perilau comanda uma busca de grande proporção contra eles.

Crisio é da mesma estirpe das velhas que, em Lúcio ou o asno e $O$ asno de ouro (IV.7) servia aos bandidos. ${ }^{9}$ Nesse último romance, os bandidos reunidos na caverna também se dedicam à troca de narrativas sobre suas excursões (Apuleio, IV.9-21). Não só eles contam histórias, mas a moça por eles aprisionada, narra à velha, a quem cabe vigiá-la, seus infortúnios (Apuleio, IV.26-27). O triste relato da moça, instiga a senhora a desfiar, por sua vez, "lindas histórias e contos de gente velha", que possam distrai-la de suas aflições (Apuleio, IV.27), dando em seguida início aquela que é a mais longa e conhecida narrativa intercalada dos romances supérstites, dedicada aos amores de Eros e Psiqué (Apuleio, IV.28-VI. 24).

A princípio a velha Crisio, em Efesíacas, teria a intenção de distrair os bandidos no serão após o jantar, provavelmente uma de suas atribuições. Secundariamente, o relato cumpre a função, involuntária, mas importante para o desenvolvimento da trama, de informar Habrocomes sobre a sorte de Ântia. Isso já havia acontecido quando Hipótoo, como corolário ao relato que faz de sua própria história, menciona a moça com que os bandidos se depararam na Cilicia (Efesíacas III.3):

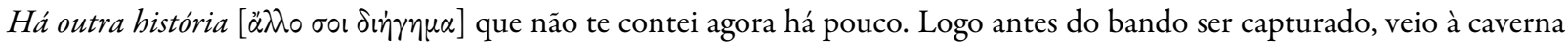
uma bela moça que andava a esmo. Ela tinha a mesma idade que você e dizia ser da sua cidade natal. Nada mais sei. Decidiuse sacrificá-la a Ares. Estava tudo preparado e os perseguidores atacaram. E então eu fugi, mas quanto a ela, não sei o que aconteceu. Era muito bela, Habrocomes, e estava vestida com simplicidade; cabelos loiros, olhos graciosos... 
Desconfiado que a tal moça pudesse ser Ântia, Habrocomes convence o companheiro a voltar a Cilícia para tentar encontrá-la. O narrador não deixa claro com que intenção o bandido conta essa história, mas fica a sugestão que, a parte o interesse intrínseco que o destino de uma moça conterrânea de Habrocomes pudesse despertar em seu ouvinte, ele estivesse considerando que talvez ela fosse a moça que ele buscava.

De volta a Crisio, sua história em nada lembra a da velha de $O$ asno de ouro, um primor narrativo de grande extensão e apuro. Como é característico do romance de Xenofonte, sua narrativa é modesta. Ela enfatiza o aspecto patético, que têm origem em um fato real -e, não, como é o caso de $O$ asno de ouro, de natureza ficcional. Com exceção dos relatos de Ântia, inventados para manipular os interlocutores, as demais narrativas intercaladas de Efesíacas têm essa característica, são relatos confessionais ou com base na realidade, haja visto as histórias de Hipótoo e Egialeu. Há na história da noiva que comete suicídio no dia do casamento e, depois, tem seu túmulo violado por piratas, que sequestram seu corpo, algo de inusitado e trágico, que vale o relato, acredita a velha.

Seria um indício que as desventuras de Ântia teriam ganhado notoriedade? Há um passo do romance em que a própria personagem parece sugerir que seja esse o caso. Quando Hipótoo reconhece a jovem, que o rufião apregoava no mercado de escravos na Itália, como a prisioneira que condenara à cova com cães famintos no Egito, ela, que não o reconhece, o interpela da seguinte maneira (Efesíacas V. 9):

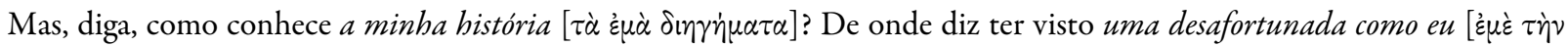

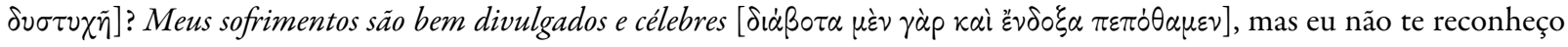
em absoluto.

A fala é curiosa porque, à exceção do relato de Crisio, do qual nada poderia saber Ântia, não há outra evidência no romance de que suas desventuras teriam se tornado célebres. No entanto, quando se lê as duas passagens em conjunto, parece haver a sugestão de isso tenha se passado. Chamo atenção, inclusive, para certa recorrência vocabular, em que se emprega para a heroína o adjetivo dustuchés, desafortunada e variantes

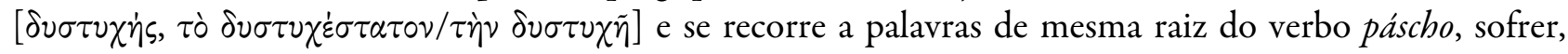
$[\pi \dot{\alpha} \sigma \chi \omega, \pi \dot{\alpha} \theta 0 \nu \varsigma / \pi \varepsilon \pi \dot{\dot{\theta}} \theta \alpha \mu \varepsilon \nu]$ para caracterizá-la. Ainda mais significativo é a presença do termo diegémata

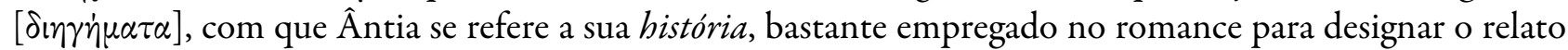
biográfico de um personagem. O relato de Crisio é definido pela mesma palavra (Efesíacas III.9): "Quando os membros do bando passaram à bebida, uma senhora, de nome Crisio, que estava ali, começou a contar

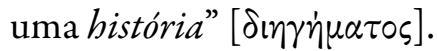

O termo ocorre dez vezes no romance, sempre em conexão com as histórias que os personagens contam, relatos que nada têm de banal, mas, ao contrário, são marcados pelo patético. ${ }^{10}$ A primeira menção, bastante significativa, acontece quando Hipótoo relata a Habrocomes um episódio marcante de sua vida, que ele

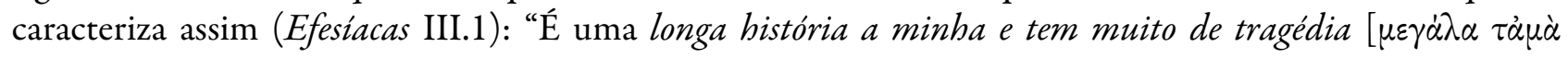

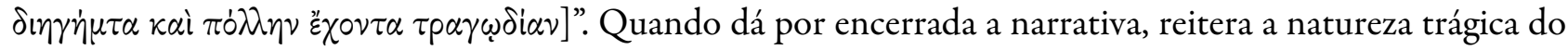

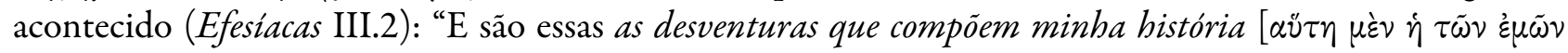
$\underline{\delta i \eta \gamma \eta \mu \dot{\alpha} \tau \omega \nu} \tau \dot{u} \chi \eta]$."

Hipótoo classifica sua narrativa (longa, trágica, desventurada) de forma semelhante a como Crisio se refere à de Ântia (triste, cheia de infortúnios). A própria moça a vê dessa maneira ao se referir a si mesma como àquela que experimentou sofrimentos dignos de serem narrados. Parecem todos concordar que o caráter patético é o que torna uma história digna de interesse, apontando para um elemento central na poética antiga, opáthos [ $\left.\pi \dot{\dot{\alpha}} \mathrm{O}_{\mathrm{s}}\right]$, um dos elementos psicagógicos da fábula trágica para Aristóteles, fator desencadeante da catarse. Assim, as vidas de Hipótoo, Ântia, Habrocomes e outros personagens do romance, eivadas de peripécias e desventuras, alimentam as narrativas internas. ${ }^{11}$ Daí a velha Crisio achar que os ladrões se interessariam em escutar a história da noiva desafortunada, que, não por coincidência, é a da heroína do romance. Ou seja, o narrador dá uma piscadinha para o leitor e sugere que a vida de Ântia daria um romance, valorizando assim o seu enredo. 
Se a história de Ântia já era conhecida enquanto ela percorria o Mediterrâneo é incerto, já que não há outras piscadelas desse tipo na trama. Sabe-se pelo comentário que faz para Hipótoo que ela acreditava ser assim, que sua história era famosa. O certo é que, em seu retorno a Éfeso, Ântia e Habrocomes redigem suas aventuras e a dedicam à deusa Ártemis (Efesíacas V.15):

Quando desembarcaram, foram imediatamente, do jeito que estavam, ao templo de Ártemis, onde, após rezar e sacrificar, dedicaram outras oferendas e, inclusive, ofertaram para a deusa o relato por escrito de tudo quanto passaram e quando fizeram

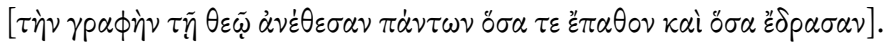

Em parte, ex-voto para louvar à deusa pelo fim das provações e sua salvação, o registro escrito da história do casal apaixonado, que, não nos furtemos de especular, seria coincidente com o romance de Xenofonte de Éfeso, evidencia essas qualidades que só têm a ganhar no contraste com o fecho feliz.

Vale ressaltar que mais uma vez Ântia procura controlar sua reputação e seus interlocutores. Ao sugerir a Hipótoo que sua vida é digna de ser narrada, ela busca suscitar nele interesse, simpatia e, assim, garantir seu resgate e salvação. De forma complementar, a confecção do livro que o casal deposita no templo de Ártemis remete à célebre passagem da Ilíada III.125-128, em que se descreve Helena ao tear, a bordar "muitas provações/dos troianos doma-cavalos e dos aqueus de túnica-brônzea,/as quais por causa dela sofriam sob a palma de Ares", reveladora não só da consciência da fama adquirida como do compromisso com a permanência da memória de seus protagonistas. ${ }^{12}$

\section{TEXTOS E COMENTÁRIOS}

Henderson, J. (ed.) (2009). Longus; Xenophon of Ephesus. Daphnis and Chloe; Antia and Habrocomes. CambridgeMassachusetts: Cambridge University Press.

O'Sullivan, J. N. (ed.) (2005). Xenophon Ephesius. De Antia et Habrocome Ephesiacorum Libri V. (Bibliotheca Teubneriana). München and Leipzig: K. G. Saur.

\section{Bibliografia REFERIDA}

Alvares, J. (1995). The drama of Hippothous in Xenophon of Ephesus' Ephesiaca. CJ. 90: 393-404.

Bowie, E. (2002). The chronology of the earlier Greek novels since B. E. Perry: revisions and precisions. Ancient Narrative 2, 47-63.

Duarte, A, S. (2018). A história de Egialeu (Efesíacas, V.1): tradução e comentário. Rónai. Revista de Estudos Clássicos e Tradutórios 6: 141-148.

Duarte, A, S. (2017). A história de Hipótoo (Efesiacas, III.2): tradução e comentário. Translatio 14: 218-226.

Gärtner, H. (1983). Xenophon von Ephesus. In A. Pauly, et al. (Eds.), Realencyclopädie der classichen Altertumwissenschaft, IX A 2: 2055-2059.

Hägg, T. (1966). Die Ephesiaka des Xenophon Ephesios - Original oder Epitome? Classica et Mediaevalia 27: 118-161.

Kytzler, B. (2003). Xenophon of Ephesus. In Schmeling, G. (Ed.), The novel in the ancient world (pp. 336-360). Boston: Brill.

Longrigg, J. (2000). Epilepsy in ancient Greek medicine-the vital step. Seizure. European Journal of Epilepsy 9: 12-21.

Morgan, J. R. (2004). Xenophon of Ephesus. En I. De Jong; R. Nunlist; A. Bowie (Eds.), Narrators, narratees, and narratives in ancient Greek literature (pp. 489-492). Leiden: Brill.

O'Sullivan, J. N. (2014). Xenophon, The Ephesian tales. En P. Cueva; S. Byrne (Eds), A Companion to the Ancient Novel (pp. 43-61). Oxford: Wiley Blackwell.

O'Sullivan, J. N. (1995). Xenophon of Ephesus: his compositional technique and the birth of novel. Berlin: Walter de Gruyter. 
Ruiz-Montero, C. (2004). Xenophon of Ephesus and Orality in the Roman Empire. Ancient Narrative 3: 43-62.

Tagliabue, A. (2017). Xenophon's Ephesiaca. A paraliterary love-story from the ancient world. Groningen: Barkhuis \& Groningen University Library.

\section{Notas}

1 Esse artigo resulta de projeto financiado pelo CNPq através da Bolsa de Produtividade em pesquisa, 303671/2015-7.

2 Os primeiros parágrafos desse texto são de contextualização e retomam em maior ou menor grau informações que constam de artigos elaborados anteriormente. Cf. Duarte (2018) e (2017).

3 Salvo menção e contrário, as traduções são de minha autoria.

4 No corpo da citação O'Sullivan remete ao seu livro de 1995. listado na bibliografia. Veja-se também Ruiz-Montero (2004, p. 44), para aproximação com o conto popular, mas também com as exibições retóricas.

5 Bowie (2002) localiza ambos no séc I d.C., embora tenha Cáriton de Afrodísias como precursor do gênero, considerando que ele teria escrito Quéreas e Calírroe entre 41 e 62 d.C, enquanto Xenofonte teria composto seu livro no final do século ou no início de II d.C. Essa cronologia é a mais aceita, embora O'Sullivan (1995) defenda que Xenofonte é mais antigo, tendo sido ele a influenciar Cáriton e, não, o contrário.

6 Cf. Morgan (2004, pp. 490-491).

7 Cf. Longrigg (2000).

8 Infelizmente o texto está corrompido nessa passagem. Os editores sugerem complementar com algo genérico como $<\mu \varepsilon \dot{\varepsilon}$

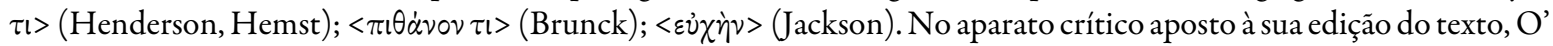
Sullivan não informa o tamanho da lacuna, mas pelas sugestões, não devia ser grande o suficiente para incluir o argumento propriamente dito.

9 Cf. $O$ asno de ouro, tradução de Ruth Guimarães (Apuleio, $O$ asno de ouro. Introdução, tradução e notas de Ruth Guimarães. São Paulo: Edidora Cultrix, 1963): "Havia lá uma velha, curvada ao peso dos anos, que parecia encarregada de zelar, ela sozinha, pelo bem-estar e pela vida de toda aquela súcia de moços”. Ver também Lúcio ou o asno (LA. 20), tradução de Custódio Magueijo (Eu, Lúcio-Memórias de um Burro. In Luciano II, Coimbra: Imprensa da Universidade de Coimbra, 2012, pp. 17-60.): "Lá dentro [i.e, da caverna], estava sentada uma velha, e também ardia uma grande fogueira”.

10 As dez ocorrências da palavra em Efesíacas estão distribuídas da seguinte maneira: Efesíacas, III.1, III. $2 .$, III.3 (nos três casos empregada por Hipótoo), III.9, por duas vezes (sobre Crisio), IV.4 (sobre o depoimento de Habrocomes ao governador do Egito), V.1 (sobre o relato de Egialeu), V.9 (empregada por Ântia); V.10 (por Habrocomes em Rodes), V.13 (para caracterizar os relatos que Habrocomes, Ântia, Leucon e Rodha trocam ao se reencontrar em Rodes). A essas se somam quinze ocorrências do verbo diegéomai $[\delta \eta \eta \gamma \varepsilon \dot{\varepsilon} \mu \alpha \iota]$, praticamente todas no mesmo contexto de histórias narradas.

11 Além dos personagens já citados, Eudoxo, Egialeu, Leucon e Rhoda também dão a conhecer seus infortúnios.

12 A tradução citada é a de Christian Werner em Homero. (2018) Ilíada. São Paulo, Sesi Editora / Ubu.

\section{BY-NC-SA}

